\title{
Kronik Yaygın Muskuloskeletal Ağrısı Olan Hastalarda Vitamin D Düzeyinin Belirlenmesi: Pilot Çalışma
}

\author{
Bahar Dernek (우
}

İstanbul Fizik Tedavi Rehabilitasyon Eğitim ve Araştırma Hastanesi, Istanbul, Türkiye

Bahar Dernek, Doç. Dr.

Iletişim:

Doç. Dr. Bahar Dernek

İstanbul Fizik Tedavi Rehabilitasyon Eğitim ve Araştırma Hastanesi, Istanbul, Türkiye

Tel: +90 5397170944

E-Posta: bahardernek@gmail.com

Gönderilme Tarihi : 18 Haziran 2018

Revizyon Tarihi : 02 Temmuz 2018

Kabul Tarihi : : 03 Temmuz 2018
ÖZET

Amaç: D Vitamini özellikle kemik gelişiminde ve çeşitli muskuloskeletal fonksiyonlarda önemli role sahiptir. Kemikle ilgili herhangi bir patolojinin tespit edilmediği olgularda özellikle bel, sırt, kosta, alt ekstremite, pelvis bölümlerinde ağrı ortaya çıkabilmektedir. Bu çalışmada amacımız kronik yaygın ağı ile gelen hastalarda vitamin D düzeyinin belirlenmesidir.

Hastalar ve Yöntemler: Ocak 2012 ile Nisan 2014 tarihleri arasında hastanemizin fiziksel tıp ve rehabilitasyon polikliniğine yaygın ağı şikayetiyle gelen hastaların verileri değerlendirmeye alındı. Hastaların ağı şiddeti (Vizüel Analog Skala, VAS) ve laboratuvar incelemeleri geriye dönük incelemelerle değerlendirildi. Romatolojik hastalığı olanlar, kanser hastaları, post-menopozal kadın hastaların verileri değerlendirme dışı bırakıldı.

Bulgular: Çalışmaya dahil edilen hasta sayııı 504 idi. Hastaların \%92,7 si kadın iken \%7,3'ü erkek idi. D vitamini düzeylerine göre sınıflandırma yapıldığında hastaların $\% 0,6$ 'sında D vitamini yeterli, $\% 1,4^{\prime}$ 'ünde D vitamini yetersiz idi. Hastaların $\% 98$ 'inde ise D vitaminin değişik derecelerde eksikliği tespit edildi (\%19,0 hafif, $\% 55,2$ orta, $\% 23,8$ ciddi eksiklik). Hastaların VAS düzeylerine göre değerlendirme yapıldığında özellikle D vitamini seviyesi düşük olanlarda VAS değerinin anlamlı derecede yüksek olduğu tespit edildi $(p<0,001)$.

Sonuç: Çalışmamızda yaygın muskuloskeletal ağıısı olan ve altta yatan sistemik, romatolojik hastalığı olmayan hastalarda D vitamini seviyesinin düşük olduğu ve D vitamini seviyesi azaldıkça VAS değerinde anlamlı oranda artış olduğu tespit edilmiştir

Anahtar sözcükler: D vitamini, kronik yaygın ağrı, tedavi

DETERMINATION OF VITAMIN D LEVELS IN PATIENTS WITH CHRONIC WIDESPREAD MUSCULOSKELETAL PAIN: A PILOT STUDY

\section{ABSTRACT}

Objectives: Vitamin D plays an important role, especially in bone development and various musculoskeletal functions. In cases where no pathology related to the bone is detected, pain may still occur, especially in the lower back, lower extremities and pelvis. Our aim in this study wass to determine the vitamin D level in patients with chronic widespread pain.

Patients and Methods: Between January 2012 and April 2014, the data of patients who complained of widespread pain at the physical medicine and rehabilitation outpatient clinic of our hospital were evaluated. The patients' pain severity (Visual Analogue Scale, VAS) and laboratory examinations were evaluated retrospectively. Patients with rheumatic disease, cancer patients and post-menopausal women were excluded from the evaluation.

Results: The number of patients included in the study was $504.92 .7 \%$ of the patients were female and $7.3 \%$ were male. Vitamin D levels were classified as adequate in $0.6 \%$ of patients and inadequate in $1.4 \%$ of patients. In $98 \%$ of patients, vitamin D deficiency was found at various grades ( $19.0 \%$ mild, $55.2 \%$ moderate, $23.8 \%$ serious deficiency). When evaluated alongside the VAS of the patients, VAS was found to be significantly higher in patients with low vitamin D levels $(p<0.001)$.

Conclusion: In our study, it was determined that the level of vitamin D was low in patients with generalized musculoskeletal pain or with underlying systemic and rheumatological diseases, and the VAS increased significantly when vitamin D levels decreased.

Keywords: Vitamin D, chronic pain, treatment 
D Vitamini sadece kemikler üzerine değil, son yıllarda çeşitli hastalıklar üzerinde de olumlu etkileri olduğu tespit edilen bir hormondur. D Vitamini esas etkisini serum kalsiyum değerlerini belli sınırlar içinde tutarak göstermektedir. Özellikle kemik formasyonunun sağlanması, re-modelling üzerine etkileri bulunmakla beraber, kas fonksiyonu üzerinde de etkileri bulunmaktadır. Bunu dışında özellikle nöromusküler fonksiyonun sağlanması, enflamasyonun azaltılması ve kronik birçok hastalığın (çeşitli kanserler, otoimmün hastalıklar, enfeksiyöz hastalıklar, kardiyovasküler hastalıklar, vb.) riskinin azaltması gibi etkileri de bulunmaktadır (1-5). Çalışmalar, D vitamininin ağrı tedavisinde, anatomik, nörolojik ve immünolojik etkilerinin olduğunu göstermiştir. Dolayısıyla D vitamini, kronik ağrının etiyolojisinde ve kronik ağrı durumlarının ve bu durumların oluşturduğu komorbiditenin tedavisinde etkin rol oynayabilir (1-4). Fibromiyalji başta olmak üzere yaygın kas iskelet sistemi ağrısını inceleyen çalışmalardaki sonuçlar net veriler ortaya koyamamaktadır. Ayrıca, D vitamini eksikliği ile kronik ağrı ilişkisindeki sınır değerlerin ortaya konması pek de mümkün değildir. $\mathrm{Bu}$ pilot çalışmada amacımız polikliniğimize başvuran, kronik yaygın ağrısı olan hastalarda D vitamini düzeylerinin belirlenmesi olmuştur.

\section{Hastalar ve yöntemler}

Ocak 2012 ile Nisan 2016 tarihleri arasında hastanemizin fiziksel tıp ve rehabilitasyon polikliniğine yaygın ağrı şikâyetiyle başvuran hastaların verileri değerlendirmeye alındı. Hastaların laboratuvar incelemeleri retrospektif olarak değerlendirildi. Romatolojik hastalığı olanlar, kanser hastaları ve osteoporoz hastalarının verileri değerlendirme dışı bırakıldı. Kayıtlarımızda yapılan inceleme sonucu toplam 1747 hasta verisi bulundu ve bu hasta verileri çalışmaya uygunluk açısından taranıp değerlendirildi. Taranan hasta verisinden 327 hastada osteoporoz, 65 hastada romatolojik hastalık, 37 hastada çeşitli kanser türleri (önceden geçirilmiş ve yeni tanı konulmuş olgular) olması nedeniyle bu hastalar değerlendirme dışı bırakıldı. Sonuç olarak 1318 hastanın verileri çalışma için değerlendirmeye uygun bulundu (Şekil 1). Hastaların D vitamini değerlerine göre sınıflandırma yapıldığında $30 \mathrm{ng} / \mathrm{mL}$ üzeri normal olarak kabul edilerek, $21-29 \mathrm{ng} / \mathrm{mL}$ seviyesi $D$ vitamini yetersizliği, 11-20 ng/mL seviyesi hafif eksiklik, 5-10 ng/mL seviyesi orta eksiklik, $<5 \mathrm{ng} / \mathrm{mL}$ seviyesi ise ciddi eksiklik olarak kabul edildi.

\section{Bulgular}

Çalışmaya dahil edilen 1318 hastanın \%89,7'si kadın iken \%10,3'ü erkek idi. Hastaların yaşları 13 ila 89 yaşlarında değişmekte idi ve ortalama ( \pm SS) hasta yaşı $41,2( \pm 15,2)$ idi. Hastaların çoğunluğunu (\%75'ini) ev hanımları oluşturmaktaydı, çoğunluğu (\%90.1) evli ve çocuk sahibi $(\% 90,0)$ idi (Tablo 1).

Tablo 1. Hastaların demografik ve klinik karakteristikleri

\begin{tabular}{|c|c|c|c|c|c|c|}
\hline \multirow[b]{2}{*}{ Yaş } & \multicolumn{2}{|c|}{$\begin{array}{l}\text { Minimum-. } \\
\text { Maksimum }\end{array}$} & \multirow{2}{*}{$\begin{array}{c}\text { Medyan } \\
40\end{array}$} & \multicolumn{3}{|c|}{ Ort. $\pm S S / n-\%$} \\
\hline & 13 & 89 & & 41.2 & \pm & 15.2 \\
\hline $13-30$ & & & & 284 & & $21.5 \%$ \\
\hline $31-45$ & & & & 579 & & $43.9 \%$ \\
\hline $46-60$ & & & & 357 & & $27.1 \%$ \\
\hline $61-75$ & & & & 81 & & $6.1 \%$ \\
\hline $76-89$ & & & & 17 & & $1.3 \%$ \\
\hline \multicolumn{7}{|l|}{ Cinsiyet } \\
\hline Kadın & & & & 1182 & & $89.7 \%$ \\
\hline Erkek & & & & 136 & & $10.3 \%$ \\
\hline \multicolumn{7}{|l|}{ Meslek } \\
\hline Ev Hanımı & & & & 989 & & $75.0 \%$ \\
\hline İşçi & & & & 177 & & $13.4 \%$ \\
\hline Serbest & & & & 42 & & $3.2 \%$ \\
\hline Öğretmen & & & & 12 & & $0.9 \%$ \\
\hline Çalışan & & & & 77 & & $5.8 \%$ \\
\hline Öğrenci & & & & 21 & & $1.6 \%$ \\
\hline \multicolumn{7}{|l|}{ Medeni Durum } \\
\hline Evli & & & & 1188 & & $90.1 \%$ \\
\hline Bekar & & & & 130 & & $9.9 \%$ \\
\hline \multicolumn{7}{|l|}{ Çocuk } \\
\hline Yok & & & & 120 & & $9.1 \%$ \\
\hline Var & & & & 1198 & & $90.9 \%$ \\
\hline \multicolumn{7}{|l|}{ Çocuk Sayısı } \\
\hline I & & & & 630 & & $52.6 \%$ \\
\hline II & & & & 295 & & $24.6 \%$ \\
\hline III & & & & 175 & & $14.6 \%$ \\
\hline IV & & & & 88 & & $7.3 \%$ \\
\hline VAS & 4.0 & 9.0 & 8 & 7.6 & \pm & .9 \\
\hline D-Vitamini (ng/mL) & 3.0 & $\begin{array}{l}-\quad 46.8 \\
\end{array}$ & 8 & 9.7 & \pm & 6.0 \\
\hline$\leq 5$ & & & & 313 & & $23.7 \%$ \\
\hline $5-10$ & & & & 568 & & $43.1 \%$ \\
\hline $11-20$ & & & & 355 & & $26.9 \%$ \\
\hline $21-29$ & & & & 69 & & $5.2 \%$ \\
\hline$\geq 30$ & & & & 13 & & $1.0 \%$ \\
\hline
\end{tabular}




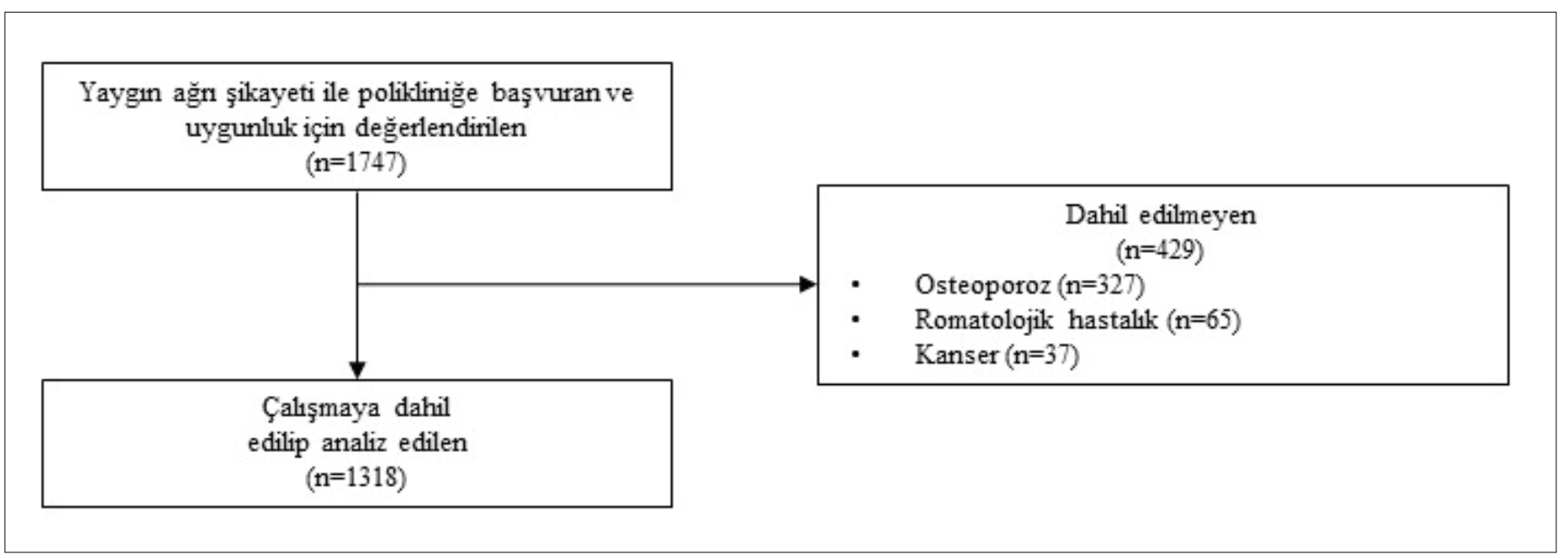

Şekil 1. Hastaların seçim kriterleri

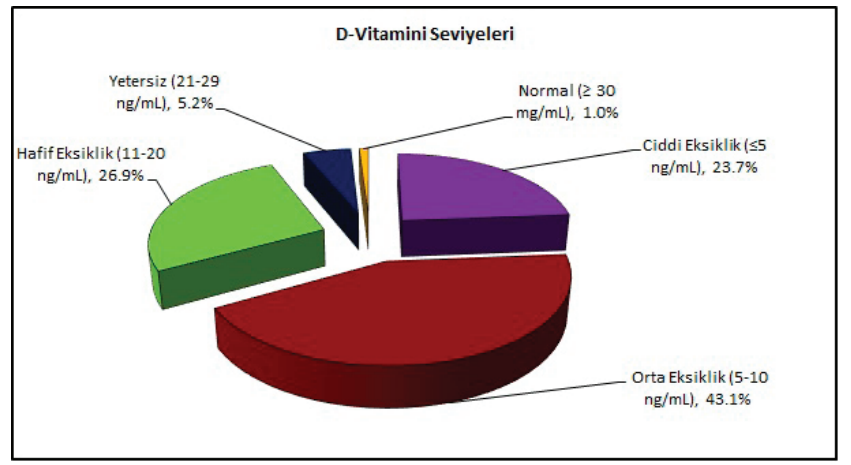

Şekil 2. Hastalarda D vitamini seviyelerinin dağııımı

D vitamini düzeylerine göre sınıflandırma yapıldığında, hastaların \%1'inde D vitamininin yeterli seviyede olduğu saptanırken, $\% 5,2$ 'sinde ise $D$ vitamini yetersizliği olduğu belirlendi. Hastaların \%93,8'inde ise D vitaminin değişik derecelerde eksikliği tespit edildi (\%43,1'inde orta, $\% 26,9$ 'unda hafif, \%23,7'sinde ciddi eksiklik, Şekil 2).

\section{Tartışma}

D vitamini yağda çözünen sekosteroid yapıda bir hormondur. D vitaminin farklı yapılarda bulunabilmekte olup, en sık rastlanılan formları vitamin D3 (kolekalsiferol) ve vitamin D2'dir (ergokalsiferol). Deride 7-dehidrokolestreolden ultraviyole radyasyon (290-320 nm) ile previtamin D3'e çevrilir. Güneş ışınına tüm vücut maruz kalırsa 30 dakikada yaklaşık 10000-20000 IU D vitamini sentezlenebilir. Deride oluşan form kandan karaciğere taşınır ve $25 \mathrm{OH}$ D vitamini (kalsidiol) elde edilir. Ardından böbreklerde aktif formu olan 1,25 dihidroksi vitamin D'ye sentezlenir $(1,6)$. Ağrı, insan doğasında var olan en sık sorunlardan biridir. Ağrı, "International Association for the Study of Pain (IASP)" tarafından genellikle doku hasarına bağlı ortaya çıkan olumsuz duygular olarak tanımlanır (7). Ağrı, esas olarak sinir sistemindeki nosiseptörlerden köken alır ancak ağrının vücutta tanımlanması beyinde yapılmaktadır. Doku hasarının giderilmesine karşın 3 aydan daha uzun süren ağrıya kronik ağrı denilmektedir (8).

Ağrı ve D vitamini arasındaki ilişki ve altında yatan mekanizmalar tam olarak açığa kavuşturulamamıştır. Ancak vitamin D'nin ağrı algısı üzerindeki anatomik ve fizyolojik etkileri konusu kabul edilmektedir (6-8). Uzun süren $D$ vitamini eksikliği zayıf immün sisteme ve kronik enflamasyona neden olabilmektedir (9-12). D vitamini eksikliği birçok kronik hastalıkla (fibromiyalji, enflamatuar ağrı, nöropatik ağrı, vb.) ve bu hastalıklardaki kronik ağrı ile ilişkilendirilse de $D$ vitaminin bu hastalıklarda ortaya çıkan ağrı patogenezinde hangi mekanizmalarla etkili olduğu net değildir $(13,14)$. D vitamin ağrı dışında anksiyete, depresyon ve uyku bozukluklarına yol açabilmektedir (9-11). D vitaminin sekonder olarak veya dolaylı olarak yaygın ağrıya yol açabildiği de düşünülmektedir. Mc Cabe ve arkadaşlarının yaptığı bir çalışmada D vitamin eksikliğinin olduğu erkek hastalarda BMI yüksekliği ve depresyonun sık rastlandığı ve bu durumun da D vitamini eksikliği ile ilişkili olabileceği belirtilmiştir. Erkeklerde D vitamin eksikliğinin direkt olarak kronik yaygın ağrıya neden olmadığı belirtilmiştir (14). Heuch ve arkadaşlarının yaptığı bir çalışmada D vitamini eksikliğinin kronik bel ağrısı ile olan ilişkisi incelenmiş ancak arada net bir ilişki olduğu tespit edilememiştir. Ancak D vitamini sentezinin ve dolayısıyla $D$ vitaminine maruz kalma süresinin toplumlar arasında farklılık göstermesi sebebiyle bu çalışmanın sonuçlarının tüm topluluklar açısından genelleme yapılmasına uygun olmadığı da belirtilmiştir (15). Kronik ağrı ile ilişkili kas iskelet sistemi hastalıkları enflamatuar eklem hastalıkları veya bağ doku hastalıkları, yumuşak doku romatizması, osteoartrit, non-spesifik bel 
ağrısı, osteoporoz olarak sayılabilir (16). Bunun dışında D vitamini eksikliği herhangi bir hastalık başlığı altında olmadan kronik yaygın ağrı ile de ilişkilendirilebilmektedir. Mekanizma olarak $D$ vitaminin hücresel düzeyde mekanizmalarla kronik ağrının gelişimi ve modülasyonu üzerinde etkili olduğu düşünülmektedir (17). D vitamini vücutta nöroaktif steroid gibi görev almakta, nötrofinlerin modülasyonu, prostaglandinlerin modülasyonu, enflamatuar yolakların modülasyonu, nitrik oksit sentez ve $T$ helper hücrelerin inhibisyonu gibi işlevleri bulunmaktadır $(18,19)$. D vitamini tedavisinin kronik ağrı tedavisinde tam olarak nasıl bir mekanizma ile etki ettiği bilinmemektedir (17). Bir derlemede, kronik ağrı durumlarında D vitaminin etkinliğini inceleyen çift kör çalışmalar incelenmiş ve $D$ vitaminin kronik ağrı tedavisindeki yerinin tartışmalı olduğu sonucuna ulaşılmıştır. Bir meta analizde 1854 hasta ve 7850 kontrol hasta değerlendirilmiş ve kronik yaygın ağrının D vitamin eksikliği ile ilişkili olduğu tespit edilmiştir. Bir kısa derlemede ise çeşitli vaka serileri ve tek kollu gözlemsel çalışmalar incelenmiş ve vitamin D eksikliği ile kas iskelet ağrısı arasında bir korelasyon tespit edilmiştir (20). 2009 ve 2011 yıllarında yayınlanan iki sistemik derlemede, D vitamin eksikliği ile yaygın ağrı

\section{Kaynaklar}

1. Shipton EA, Shipton EE. Vitamin D and Pain: Vitamin D and Its Role in the Aetiology and Maintenance of Chronic Pain States and Associated Comorbidities. Pain Res Treat 2015;2015:904967. [CrossRef]

2. Holick MF. Vitamin D deficiency. New Engl J Med 2007;357:266-81. [CrossRef]

3. Plotnikoff GA, Quigley JM. Prevalence of severe hypovitaminosis D in patients with persistent, nonspecific musculoskeletal pain. Mayo Clin Proc 2003;78:1463-70. [CrossRef]

4. Cutolo M, Paolino S, Sulli A, Smith V, Pizzorni C, Seriolo B. Vitamin $\mathrm{D}$, steroid hormones, and autoimmunity. Ann $\mathrm{N}$ Y Acad Sci 2014;1317:39-46. [CrossRef]

5. Jesus CAS, Feder D, Peres MFP. The role of vitamin $D$ in pathophysiology and treatment of fibromyalgia. Curr Pain Headache Rep 2013;17:355. [CrossRef]

6. Brannon PM. Key questions in Vitamin D research. Scand J Clin Lab Invest Suppl 2012;243:154-62. [CrossRef]

7. Merskey H, Bogduk N. Classification of Chronic Pain: Descriptions of Chronic Pain Syndromes and Definitions of Pain Terms, 2nd ed. Seattle, Wash, USA: IASP Press; 1994. https://s3.amazonaws.com/ rdcms-iasp/files/production/public/Content/ContentFolders/ Publications2/FreeBooks/Classification-of-Chronic-Pain.pdf

8. International Association for the Study of Pain. Classification of chronic pain. Descriptions of chronic pain syndromes and definitions of pain terms. Prepared by the International Association for the Study of Pain, Subcommittee on Taxonomy. Pain Suppl 1986;3:S1-226. arasındaki ilişkinin çelişkili olduğu belirtilmiş ve özellikle çalışma kapsamında değerlendirilen hastaların arasında romatoid artrit gibi romatolojik hastalıklar veya lokalize kas iskelet ağıı olmasının sonuçları etkileyebildiği belirtilmiştir $(21,22)$. Bir meta analizde D vitamin eksikliği ile kronik yaygın ağrı arasında pozitif bir ilişki bulunmuştur. Özellikle D vitaminin 8-10 $\mathrm{ng} / \mathrm{mL}$ arasında olması kronik yaygın ağrı gelişimi için eşik değer olarak kabul edilmiştir. Bizim çalışmamızda da kronik yaygın ağrı ile $D$ vitamini eksikliği arasında anlamlı oranda bir ilişki olduğu tespit edilmiştir. Çalışmamıza romatolojik hastalıklar, kanser, osteoporoz gibi hastalıkları olan hastaların dahil edilmemesi, çalışmamızın sonuçlarının anlamlı olmasına yardımcı olduğu kanaatindeyiz. Çalışmamızın eksik yanları arasında prospektif bir çalışma olmaması, D vitamin eksikliği ile ağrı şiddeti arasındaki ilişkinin ortaya konulmaması sayılabilir. Ancak ileriye dönük, geniş örneklem büyüklüğüne sahip çalışmalar yapmak için bütçenin sağlanması ekonomik açıdan çalışmanın yapılabilirliğini zorlamaktadır. İleriye dönük yapacağımız çalışmalarda özellikle D vitamin eksikliği ile ağrı şiddeti, yaş, önceden geçirilmiş hastalıklar (sistemik veya muskuloskeletal) ilişkisini incelemek ana hedeflerimiz olacaktır.

9. Deeb KK, Trump DL, Johnson CS. Vitamin D signalling pathways in cancer: potential for anticancer therapeutics. Nature Rev Cancer 2007;7:684-700. [CrossRef]

10. Thacher TD, Clarke BL. Vitamin D insufficiency. Mayo Clin Proc 2011;86:50-60. [CrossRef]

11. Munger KL, Levin LI, Hollis BW, Howard NS, Ascherio A. Serum 25-hydroxyvitamin D levels and risk of multiple sclerosis. J Am Med Assoc 2006;296:2832-8. [CrossRef]

12. Ames BN. Low micronutrient intake may accelerate the degenerative diseases of aging through allocation of scarce micronutrient by triage. Proc Nat Acad Sci U S A 2006;103:17589-94. [CrossRef]

13. Straube S, Derry S, Moore RA, McQuay HJ.Vitamin D for the treatment of chronic painful conditions in adults. Cochrane Database Syst Rev 2015;5:CD007771. [CrossRef]

14. McCabe PS, Pye SR, Beth JM, Lee DM, Tajar A, Bartfai G, et al. Low vitamin $D$ and the risk of developing chronic widespread pain: results from the European male ageing study. BMC Musculoskelet Disord 2016;17:32. [CrossRef]

15. Heuch I, Heuch I, Hagen K, Mai XM, Langhammer A, Zwart JA. Is there an association between vitamin $D$ status and risk of chronic low back pain? A nested case-control analysis in the Nord-Trøndelag Health Study. BMJ Open 2017;7:e018521. [CrossRef]

16. Haroon M, Bond U, Quillinan N, Phelan MJ, Regan MJ. The prevalence of vitamin $D$ deficiency in consecutive new patients seen over a 6-month period in general rheumatology clinics. Clin Rheumatol 2011;30:789-94. [CrossRef]

17. Martin KR, Reid DM. Is there role for vitamin $D$ in the treatment of chronic pain? Ther Adv Musculoskelet Dis 2017;9:131-5. [CrossRef] 
18. Shipton EA, Shipton EE. Vitamin D and pain: vitamin D and its role in the aetiology and maintenance of chronic pain states and associated comorbidities. Pain Res Treat 2015;2015:904967. [CrossRef]

19. Rosen CJ, Adams JS, Bikle DD, Black DM, Demay MB, Manson JE, et al. The nonskeletal effects of vitamin D. Endocrine Society scientific statement. Endocr Rev 2012;33:456-92. [CrossRef]
20. Thuesen B, Husemoen L, Fenger M, Jakobsen J, Schwarz P, Toft U, et al. Determinants of vitamin D status in a general KR Martin and DM Reid journals. sagepub.com/home/tab 135 population of Danish adults. Bone 2012;50:605-10. [CrossRef]

21. Gill TK, Hill CL, Shanahan EM, Taylor AW, Appleton SL, Grant JF. Vitamin D levels in an Australian population. BMC Public Health 2014;14:1001. [CrossRef] 